\title{
Influência do processamento pós-colheita e armazenamento na composição química da droga vegetal e do óleo essencial de carqueja [Baccharis trimera (Less.) DC.]
}

\author{
SILVA, F.G. ${ }^{1}$; NASCIMENTO, V.E. ${ }^{2}$; PINTO, J.E.B.P. ${ }^{3}$; OLIVEIRA, C.B.A. ${ }^{4}$; SANTOS, M.R. ${ }^{4}$; FERRI, P.H. ${ }^{4}$ \\ ${ }^{1}$ Laboratório de Cultura de Tecidos Vegetais Cerrado, IFGoiano-Campus Rio Verde, Caixa Postal 66, CEP: 75901 - \\ 970, Rio Verde-Brasil *fabiano.guimaraes@pq.cnpq.br ${ }^{2}$ Laboratório de Cultura de Tecidos e Plantas Medicinais, \\ Departamento de Agricultura, Universidade Federal de Lavras, Caixa Postal 3037, CEP: 37200-000, Lavras-Brasil \\ ${ }^{3}$ Laboratório de Bioatividade Molecular, Instituto de Química, Universidade Federal de Goiás, Caixa Postal 131, \\ CEP: 74001-970, Goiânia-Brasil
}

\begin{abstract}
RESUMO: A carqueja-amarga [Baccharis trimera (Asteraceae)] é uma espécie originária do centrosul da América do Sul. Análises qualitativas e quantitativas foram realizadas utilizando-se a técnica de CG-MS, para avaliar o efeito de diferentes formas de beneficiamento pós-colheita de drogas vegetais constituídas de partes aéreas de carqueja na composição química do óleo essencial, bem como verificar variações na composição quando conservado a $-6^{\circ} \mathrm{C}$, durante 8 meses. $\mathrm{O}$ armazenamento da droga pulverizada reduziu significativamente o teor de óleo essencial, o que não aconteceu na droga fragmentada. Os teores dos constituintes majoritários espatulenol e ledol não foram influenciados pelo tratamento pós-colheita, embora tenham apresentado variações distintas redução nas concentrações de ledol e aumento nos teores de espatulenol. Verificou-se que as drogas fragmentadas podem ser armazenadas por até 12 meses e pulverizadas no momento da extração, não conferindo redução no teor de óleo essencial, nem dos constituintes químicos. $\mathrm{O}$ armazenamento a $-6^{\circ} \mathrm{C}$ por até oito meses, provocou variações quantitativas em alguns constituintes minoritários, tais como a-guaieno, b-selineno, germacreno B e espatulenol.
\end{abstract}

Palavras-chave: Baccharis, Asteraceae, plantas medicinais, óleo essencial, pós-colheita

\begin{abstract}
Influence of post-harvest processing and storage on the chemical composition of drug and essential oil from "carqueja" [Baccharis trimera (Less.) DC.]. "Carqueja-amarga" [Baccharis trimera (Asteraceae)] is a species from the central south of South America. Qualitative and quantitative analyses were performed using the technique gas chromatography coupled to mass spectrometry to evaluate the effect of different post-harvest processing forms of drugs constituted of parts of "carqueja" on the chemical composition of its essential oil. The variation in the chemical composition of the essential oil stored at $-6^{\circ} \mathrm{C}$ for up to eight months was also evaluated. Storage of powdered drug significantly reduced the essential oil content, which was not observed for fragmented drug. The concentration of the major constituents of "carqueja" essential oil, spathulenol and ledol, was not affected by the post-harvest treatment, although they presented distinct variations, with ledol concentrations reducing and spathulenol concentrations increasing. We found that fragmented drugs can be stored for up to 12 months and powdered at the moment of extraction, without reducing the concentration of the essential oil or its chemical constituents. Storage at $-6^{\circ} \mathrm{C}$ for eight months caused quantitative variations in some minor constituents of the essential oil such as a-guaiene, b-selinene, germacrene B and espathulenol.
\end{abstract}

Key words: Baccharis, Asteraceae, medicinal plants, essential oil, post-harvest

Recebido para publicação em 17/10/08

Aceito para publicação em 19/07/10

Rev. Bras. Pl. Med., Botucatu, v.12, n.4, p.436-442, 2010. 


\section{INTRODUÇÃO}

O gênero Baccharis (Asteraceae) está representado por 450 a 500 espécies, todas nativas das Américas (Nesom, 1990). Compreende largo gênero de plantas amplamente distribuído do México até a Argentina, usadas tradicionalmente como fonte terapêutica para o tratamento de diversos distúrbios relacionados à saúde do homem (Jakupovic et al., 1990; Suttisri et al., 1993; Loayza et al., 1995).

A carqueja (Baccharis trimera) é largamente utilizada na medicina popular na forma de infusão devido às propriedades antiinflamatórias, cicatrizantes e digestivas (Pedrazzi et al., 1997). É utilizada também no tratamento de reumatismo, desordens hepatobiliares, diabetes, ulcerações e ferimentos (Gene et al., 1996; Januário et al., 2004; Agra et al., 2007). Estudos realizados por Avancini et al. (2000) confirmaram a atividade antimicrobiana in vitro do decocto de $B$. trimera.

Os óleos essenciais são usados para conferir aromas especiais a inúmeros perfumes, cosméticos, sabonetes, desodorantes, preparações condimentares e doces. São empregados também para mascarar odores desagradáveis em ambiente de trabalho e instalações sanitárias, além de serem usados como solventes em produtos da indústria química, tais como, tintas, borrachas, inseticidas. Alguns óleos essenciais fornecem compostos de partida para síntese de outras substâncias úteis na indústria química e farmacêutica. Outros têm propriedades farmacológicas e são usados como antibacterianos, analgésicos, sedativos, expectorantes, estimulantes e estomáticos na composição de diversos medicamentos (Craveiro et al., 1981).

No processo biológico de produção de princípios ativos, fatores como ambiente, o manejo pós-colheita e o tempo de armazenamento podem determinar a qualidade boa ou ruim desses princípios ativos.

O presente trabalho teve como objetivo avaliar a influência de diferentes manejos pós-colheita de drogas originadas de partes aéreas de carqueja na composição química do óleo essencial, sugerindo uma sequência para o processamento pós-colheita e observação de prazo de validade. Objetivou, também, avaliar o efeito da temperatura de congelamento $\left(-6^{\circ} \mathrm{C}\right)$ na composição química do óleo essencial.

\section{MATERIAL E MÉTODO}

\section{Material vegetal}

Foram utilizados ramos de carqueja [Baccharis trimera (Less.) DC.], coletados em 26/11/ 2002 (experimentos 1 e 2) e 10/07/2003, em plena floração (experimento 3), de plantas matrizes do Horto de Plantas Medicinais da Universidade Federal de Lavras, Minas Gerais. A exsicata do material botânico encontra-se depositada no Herbário da UFLA (ESAL 169933), identificada pelo Prof. Manoel Losada Gavilanes, do Departamento de Biologia da mesma Universidade.

\section{Experimento 1}

As partes aéreas foram desidratadas em ausência de luz com o auxílio de desumidificador Arsec $160^{\circledR}$, durante três dias, sob temperatura média máxima de $30,5^{\circ} \mathrm{C}$ e média mínima de $25,5^{\circ} \mathrm{C}$. Para a extração do óleo essencial, utilizou-se amostra de $20 \mathrm{~g}$ de fitomassa seca.

Foram avaliados dois diferentes processos de beneficiamento pós-colheita cortes em fragmentos de $5 \mathrm{~cm}$ ou a moagem em moinho de facas com peneira de 10 mesh (MA 680, Marconi), combinados com 4 épocas de armazenamento (0, 4, 8 e 12 meses).

Adotou-se o delineamento experimental em blocos ao acaso, em um esquema fatorial $2 \times 4$, sendo dois modos de processamento e 4 tempos de armazenamento. Cada tratamento foi composto por três repetições, totalizando-se 24 unidades experimentais.

\section{Experimento 2}

Além dos dois processos de beneficiamento pós-colheita descritos no experimento anterior, fragmentos de $5 \mathrm{~cm}$, foram armazenados por 12 meses nas mesmas condições do referido experimento, e triturados no momento da extração, com a finalidade de avaliar o efeito deste processo na extração do óleo essencial e constituintes químicos.

\section{Experimento 3}

As partes aéreas foram desidratadas em estufa de circulação de ar forçada, durante 72 horas, à temperatura de até $35^{\circ} \mathrm{C}$. Para extração do óleo essencial, utilizou-se amostra de $30 \mathrm{~g}$ de fitomassa seca.

Foi avaliado o armazenamento do óleo essencial em congelador, à temperatura média de $-6^{\circ} \mathrm{C}$, durante 0,4 e 8 meses. Para este armazenamento, o óleo essencial foi acondicionado em frascos de vidro vedados e cobertos com papel alumínio.

O delineamento experimental foi em blocos ao acaso, sendo três tempos de armazenamento. Cada tratamento foi composto por três repetições, totalizando 9 unidades experimentais.

Nos três experimentos, os resultados foram submetidos à análise de variância (Prob $\mathrm{F}<0,05)$ e as médias comparadas pelo teste de Tukey a $5 \%$ de probabilidade, utilizando-se o programa Sistema de Análises Estatísticas e Genéticas-SAEG (Ribeiro Junior, 2001). 


\section{Extração do óleo essencial}

O óleo essencial foi extraído pela técnica de hidrodestilação (Clevenger) durante 2 horas. $O$ hidrolato foi submetido à extração com diclorometano, na proporção de $1 / 4$ do volume total, dividido em três vezes. Como dessecante, foi adicionado sulfato de magnésio anidro, durante 24 horas, sendo em seguida filtrado e levado ao evaporador rotativo à temperatura de $40^{\circ} \mathrm{C}$ e pressão de $200 \mathrm{~mm} \mathrm{Hg}$. Após evaporação do solvente, o óleo essencial foi transferido para frasco de vidro e deixado em capela de fluxo a temperatura ambiente até valores de massa constante.

\section{Análises por CG/EM}

As análises químicas foram realizadas em aparelho de cromatografia gasosa acoplada a espectrômetro quadrupolar de massas (CG-EM), Shimadzu QP5050A (Kyoto, Japão), nas condições operacionais de coluna capilar de sílica fundida, Shimadzu CBP-5 (30 m de comprimento X 0,25 mm de diâmetro interno $X 0,25 \mu \mathrm{m}$ de espessura do filme em $5 \%$ de fenilmetilpolisiloxano), com fluxo de $1 \mathrm{~mL}$ min $^{-1}$ de Hélio como gás de arraste; aquecimento com temperatura programada $\left(60^{\circ} \mathrm{C}\right.$ com gradiente de $3^{\circ} \mathrm{C}$ $\mathrm{min}^{-1}$ até $240^{\circ} \mathrm{C} \mathrm{e}$, em seguida, com um gradiente de $10^{\circ} \mathrm{C}$ min $^{-1}$ até $270^{\circ} \mathrm{C}$, mantendo-se uma isoterma de $7 \mathrm{~min}$ ). A energia de ionização do detector foi de 70 $\mathrm{eV}$, sendo o volume de injeção da amostra de $0,5 \mathrm{~mL}$ diluído em hexano (grau ultra-resíduo, Baker) e à uma razão de injeção de 1:20. As temperaturas do injetor e do detector foram mantidas em $220^{\circ} \mathrm{C}$ e $240^{\circ} \mathrm{C}$, respectivamente. A análise foi conduzida no modo varredura à velocidade de 1,0 varredura $\mathrm{s}^{-1}$, com intervalo de massas de 40-400 u.m.a. A análise quantitativa foi obtida pela integração do cromatograma total de íons (TIC). A identificação dos constituintes químicos foi realizada por comparação, automática e manual, dos espectros de massas com os das bibliotecas NIST/EPA/NHI (1998), por comparação dos espectros de massas e dos Índices de Retenção (IR) com os da literatura (Adams, 2001) e pela co-injeção com padrões autênticos, quando possível. Os Índices de Retenção foram calculados através da co-injeção com mistura de hidrocarbonetos $\mathrm{C}_{8}-\mathrm{C}_{32}$ (Sigma, EUA) e com a aplicação da equação de Dool \& Kratz (1963).

\section{RESULTADO E DISCUSSÃO}

Os teores dos constituintes químicos majoritários do óleo essencial de carqueja, espatulenol e ledol, não foram influenciados pelo beneficiamento pós-colheita. Porém, se comportaram de maneira distinta, com o ledol apresentando redução no teor com o armazenamento, enquanto que o espatulenol acréscimo, independente da forma que foram armazenados (Tabela 1). Outro constituinte majoritário, o globulol, apresentou maior teor relativo em partes aéreas de carqueja pulverizadas, imediatamente após a colheita, enquanto que o beneficiamento pós-colheita em fragmentos resultou em teor mais elevado, em qualquer tempo de armazenamento.

Quanto ao guaiol, partes aéreas fragmentadas e submetidas à extração imediatamente após a colheita, revelaram teores mais elevados. Já sob armazenamento, as partes aéreas pulverizadas foram as que resultaram em teores mais elevados.

Além dos já mencionados ledol e espatulenol, vários outros constituintes químicos como $\beta$ calacoreno, 1-epi-cubenol, $\alpha$-muurolol, himachalol e 7-epi- $\alpha$-eudesmol se mostraram indiferentes aos manejos pós-colheita.

Outros constituintes como $\beta$-cariofileno, $\sigma$ gurjuneno, germacrene $D$, trans- $\beta$-guaieno, $\alpha$ calacoreno, viridiflorol, $\alpha$-cadinol, 14-hidróxi-9-epicariofileno, cadaleno, dois derivados oxigenados de cadaleno e khusinol praticamente não foram influenciados pelo beneficiamento pós-colheita.

O teor de delta-cadineno, em partes aéreas submetidas a extração imediatamente após a colheita, não foi influenciado pelo manejo pós-colheita. No entanto, as partes aéreas fragmentadas, submetidas ao armazenamento, apresentaram teores inferiores às pulverizadas. Fragmentos de carqueja quando armazenados apresentaram teores de epóxido de humuleno II superiores aos pulverizados. Por outro lado, nesta condição pós-colheita, o teor de eudesma$4(14), 7$-dien-1- $\beta$-ol foi superior aos verificados em partes aéreas pulverizadas.

O teor de óleo essencial foi influenciado pelo tempo de armazenamento e manejo pós-colheita (Tabela 1). Não foi constatada redução no teor de óleo essencial, quando as partes aéreas de carquejas foram armazenadas na forma de fragmentos ao longo de um ano. Resultados diferentes foram encontrados quando se armazenou partes aéreas pulverizadas, constatando-se redução a partir da extração realizada imediatamente após a colheita para os demais tempos de armazenamento.

Quando se comparou os manejos pós-colheita em cada época de armazenamento, constatou-se diferença no tempo zero em partes pulverizadas, enquanto que no beneficiamento por fragmentos, no tratamento por quatro meses verificou-se um maior teor.

A extração de óleo essencial das partes aéreas de carqueja armazenadas por 12 meses, na forma de fragmentos e pulverização no momento da extração demonstrou uma tendência de maior eficiência $(0,16 \%)$, comparada a extração na forma de fragmentos $(0,11 \%)$ ou na forma armazenada pulverizada $(0,10 \%)$ (Tabela 2). O trabalho de Silva et al. (2007) demonstrou que o teor de óleo essencial de carqueja não ultrapassou $0,32 \%$. Por outro lado,

Rev. Bras. PI. Med., Botucatu, v.12, n.4, p.436-442, 2010. 


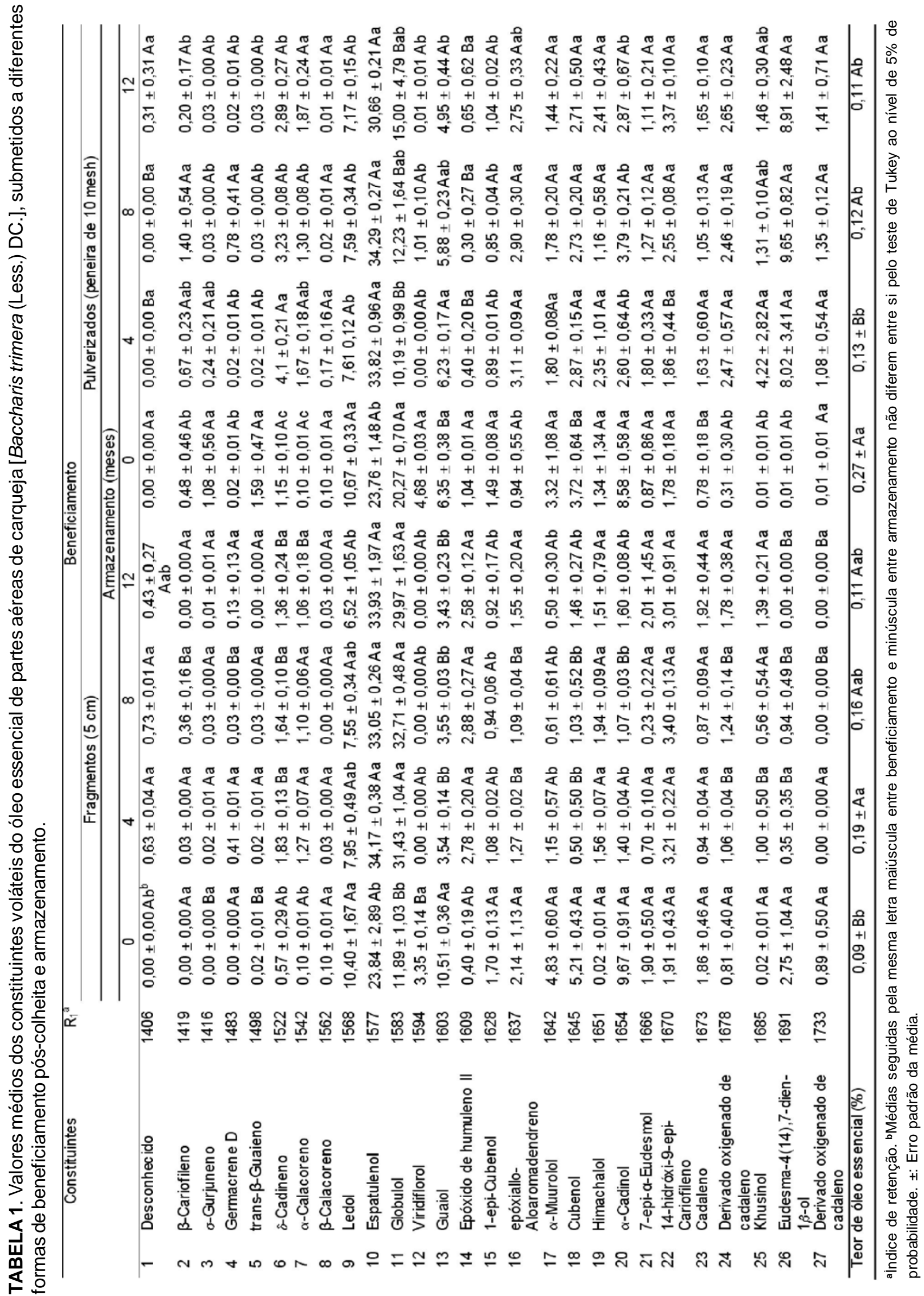

Rev. Bras. PI. Med., Botucatu, v.12, n.4, p.436-442, 2010. 
os resultados encontrados por Ferrante et al. (2007), verificaram teores entre 0,5 a $1 \%$ de óleo essencial. Estas grandes diferenças no teor do óleo essencial encontradas entre os trabalhos citados acima e os encontrados no presente trabalho podem ser explicadas pelo fato do material vegetal utilizado encontrar-se em fase de desenvolvimento e épocas de coletas diferentes, e formas e tempos de extração também diferentes.

Os teores do óleo essencial de gengibre (Zingiber officinale Roscoe) na forma de fragmentos ou moído também apresentaram diferenças significativas, com o beneficiamento na forma moída propiciando um maior teor. Diferenças também foram identificadas no material moído em relação ao fatiado, havendo evidências que os constituintes químicos mais voláteis se perderam durante o processo de moagem (Maia et al., 1991). Em gengibre, conforme aumentou o tempo de armazenamento, foi constatada redução no teor de óleo essencial, que foi atribuída à perda por evaporação dos constituintes químicos mais voláteis (Sakamura, 1987).

Neste trabalho, a avaliação da composição química dos óleos essenciais de partes aéreas de carqueja armazenadas por 12 meses na forma pulverizada, fragmentada ou desta forma, porém, pulverizada no momento da extração do óleo essencial não revelou qualquer influência, quando comparado nos diferentes tecidos, dos constituintes germacreno D, $\alpha$-calacoreno, ledol, espatulenol, viridiflorol, guaiol, 1-epi-cubenol, epóxialloaloaromadendreno, $\alpha$-muurolol, himachalol, $\alpha$-cadinol, 7-epi- $\alpha$-eudesmol, 14-hidróxi-9-epi-cariofileno, cadaleno, um derivado oxigenado de cadaleno e khusinol (Tabela 2). Apenas $\beta$-cariofileno e gamagurjuneno apresentaram teores superiores em tecidos armazenados fragmentados e pulverizados no momento da extração do óleo essencial.

O armazenamento do óleo essencial em congelador por até oito meses influenciou o teor de $\alpha$-guaieno, $\beta$-selineno, germacreno B e espatulenol

TABELA2. Valores médios dos constituintes voláteis do óleo essencial de partes aéreas de carqueja [Baccharis trimera (Less.) DC.] armazenadas por 12 meses na forma fragmentada e com a extração do óleo nesta forma (a), armazenamento na forma pulverizada (b) e armazenado na forma fragmentada e pulverizado no momento extração do óleo (c).

\begin{tabular}{|c|c|c|c|c|c|}
\hline \multicolumn{2}{|r|}{ Constituintes } & \multirow[t]{2}{*}{$\mathrm{R}_{1}^{\mathrm{a}}$} & \multicolumn{3}{|c|}{ Armazenamento por 12 meses } \\
\hline & & & a & $b$ & C \\
\hline 1 & Desconhecido & 1406 & $0,43 \pm 0,27 a^{b}$ & $0,31 \pm 0,31 a$ & $0,83 \pm 0,12 a$ \\
\hline 2 & $\beta$-Cariofileno & 1419 & $0,00 \pm 0,00 b$ & $0,20 \pm 0,17 b$ & $1,73 \pm 0,06 a$ \\
\hline 3 & $\gamma$-Gurjuneno & 1416 & $0,01 \pm 0,01 b$ & $0,03 \pm 0,00 b$ & $0,57 \pm 0,06 a$ \\
\hline 4 & Germacrene D & 1483 & $0,13 \pm 0,13 a$ & $0,02 \pm 0,01 \mathrm{a}$ & $0,16 \pm 0,15 a$ \\
\hline 5 & trans- $\beta$-Guaieno & 1498 & $0,00 \pm 0,00 a$ & $0,03 \pm 0,00 a$ & $0,03 \pm 0,00 a$ \\
\hline 6 & $\delta$-Cadineno & 1522 & $1,36 \pm 0,24 b$ & $2,89 \pm 0,27 a$ & $2,09 \pm 0,11 a b$ \\
\hline 7 & a-Calacoreno & 1542 & $1,06 \pm 0,18 a$ & $1,87 \pm 0,24 \mathrm{a}$ & $1,09 \pm 0,07 a$ \\
\hline 8 & $\beta$-Calacoreno & 1562 & $0,03 \pm 0,00 a$ & $0,01 \pm 0,01 \mathrm{a}$ & $0,67 \pm 0,64 \mathrm{a}$ \\
\hline 9 & Ledol & 1568 & $6,52 \pm 1,05 a$ & $7,17 \pm 0,15 a$ & $8,15 \pm 0,53 a$ \\
\hline 10 & Espatulenol & 1577 & $33,93 \pm 1,97 a$ & $30,66 \pm 0,21 a$ & $31,58 \pm 0,43 a$ \\
\hline 11 & Globulol & 1583 & $29,97 \pm 1,63 a$ & $15,00 \pm 4,69 b$ & $31,55 \pm 0,96 a$ \\
\hline 12 & Viridiflorol & 1594 & $0,00 \pm 0,00 a$ & $0,01 \pm 0,01 \mathrm{a}$ & $0,02 \pm 0,01 a$ \\
\hline 13 & Guaiol & 1603 & $3,43 \pm 0,23 a$ & $4,95 \pm 0,44 a$ & $3,67 \pm 0,09 a$ \\
\hline 14 & Epóxido de humuleno II & 1609 & $2,58 \pm 0,12 a b$ & $0,65 \pm 0,62 b$ & $2,77 \pm 0,18 a$ \\
\hline 15 & 1-epi-Cubenol & 1628 & $0,92 \pm 0,17 a$ & $1,04 \pm 0,02 a$ & $1,04 \pm 0,15 a$ \\
\hline 16 & epóxiallo-Aloaromadendreno & 1637 & $1,55 \pm 0,20 a$ & $2,75 \pm 0,33 a$ & $1,19 \pm 0,58 a$ \\
\hline 17 & a-Muurolol & 1642 & $0,50 \pm 0,30 a$ & $1,44 \pm 0,22 \mathrm{a}$ & $1,11 \pm 0,54 \mathrm{a}$ \\
\hline 18 & Cubenol & 1645 & $1,46 \pm 0,27 a b$ & $2,71 \pm 0,50 a$ & $0,56 \pm 0,28 b$ \\
\hline 19 & Himachalol & 1651 & $1,51 \pm 0,79 a$ & $2,41 \pm 0,43 a$ & $1,64 \pm 0,05 a$ \\
\hline 20 & a-Cadinol & 1654 & $1,60 \pm 0,08 a$ & $2,87 \pm 0,67 a$ & $1,42 \pm 0,08 \mathrm{a}$ \\
\hline 21 & 7-epi-a-Eudesmol & 1666 & $2,01 \pm 1,45 a$ & $1,11 \pm 0,21 \mathrm{a}$ & $0,03 \pm 0,00 \mathrm{a}$ \\
\hline 22 & 14-hidróxi-9-epi-Cariofileno & 1670 & $3,01 \pm 0,91 \mathrm{a}$ & $3,37 \pm 0,10 a$ & $4,26 \pm 0,12 \mathrm{a}$ \\
\hline 23 & Cadaleno & 1673 & $1,92 \pm 0,44 a$ & $1,65 \pm 0,10 a$ & $0,89 \pm 0,02 \mathrm{a}$ \\
\hline 24 & Derivado oxigenado de cadaleno & 1678 & $1,78 \pm 0,38 a$ & $2,65 \pm 0,23 a$ & $1,13 \pm 0,15 a$ \\
\hline 25 & Khusinol & 1685 & $1,39 \pm 0,21 \mathrm{a}$ & $1,46 \pm 0,30 a$ & $0,58 \pm 0,28 \mathrm{a}$ \\
\hline 26 & Eudesma-4(14),7-dien-1 $\beta$-ol & 1691 & $0,00 \pm 0,00 b$ & $8,91 \pm 2,48 a$ & $0,27 \pm 0,27 b$ \\
\hline 27 & Derivado oxigenado de cadaleno & 1733 & $0,00 \pm 0,00 a$ & $1,47 \pm 0,71 \mathrm{a}$ & $0,00 \pm 0,00 \mathrm{a}$ \\
\hline \multicolumn{3}{|c|}{ Teor de óleo essencial (\%) } & $0,11 \mathrm{a}$ & $0,10 \mathrm{a}$ & $0,16 \mathrm{a}$ \\
\hline
\end{tabular}

ấndice de retenção. bMédias seguidas pela mesma letra não diferem entre si pelo teste de Tukey ao nível de 5\% de probabilidade. \pm : Erro padrão da média.

Rev. Bras. Pl. Med., Botucatu, v.12, n.4, p.436-442, 2010. 
TABELA 3: Valores médios dos constituintes voláteis do óleo essencial de partes aéreas de carqueja [Baccharis trimera (Less.) DC.] armazenadas em congelador $\left(-6^{\circ} \mathrm{C}\right)$.

\begin{tabular}{|c|c|c|c|c|c|}
\hline & \multirow[t]{2}{*}{ Constituintes } & \multirow[t]{2}{*}{$\mathrm{R}_{l}^{\mathrm{a}}$} & \multicolumn{3}{|c|}{ Armazenamento (meses) } \\
\hline & & & 0 & 4 & 8 \\
\hline 1 & $\alpha$-Copaeno & 1376 & $0,42 \pm 0,41^{b} a$ & $0,29 \pm 0,14 a$ & $0,84 \pm 0,31 a$ \\
\hline 2 & $\beta$-Cubebeno & 1390 & $0,01 \pm 0,00 a$ & $0,01 \pm 0,00 a$ & $0,01 \pm 0,00 a$ \\
\hline 3 & $\beta$-Elemeno & 1392 & $0,30 \pm 0,14 a$ & $0,20 \pm 0,10 a$ & $0,48 \pm 0,31 a$ \\
\hline 4 & $\alpha$-Gurjuneno & 1410 & $0,49 \pm 0,36 a$ & $0,71 \pm 0,18 a$ & $0,62 \pm 0,21 a$ \\
\hline 5 & $\beta$-Cariofileno & 1420 & $14,92 \pm 0,71 \mathrm{a}$ & $14,64 \pm 0,25 a$ & $14,75 \pm 1,34 \mathrm{a}$ \\
\hline 6 & $\alpha$-Guaieno & 1439 & $2,26 \pm 0,01 a$ & $2,16 \pm 0,06 a b$ & $2,06 \pm 0,05 b$ \\
\hline 7 & $\alpha$-Humuleno & 1454 & $1,21 \pm 0,07 a$ & $1,34 \pm 0,07 a$ & $1,27 \pm 0,09 a$ \\
\hline 8 & $\gamma$-Gurjuneno & 1472 & $0,58 \pm 0,29 a$ & $0,49 \pm 0,24 a$ & $0,26 \pm 0,25 a$ \\
\hline 9 & $\gamma$-Muur ole no & 1477 & $0,97 \pm 0,09 a$ & $1,09 \pm 0,06 a$ & $0,95 \pm 0,13 a$ \\
\hline 10 & Germacreno D & 1483 & $21,78 \pm 3,45 a$ & $20,50 \pm 2,00 a$ & $24,00 \pm 2,05 a$ \\
\hline 11 & $\beta$-Selineno & 1487 & $0,01 \pm 0,00 b$ & $0,92 \pm 0,19 a$ & $0,80 \pm 0,18 a$ \\
\hline 12 & Biciclogermacreno & 1497 & $28,05 \pm 0,42 \mathrm{a}$ & $27,29 \pm 0,37 a$ & $28,96 \pm 0,59 a$ \\
\hline 13 & $\alpha$-Muuroleno & 1500 & $0,51 \pm 0,12 a$ & $0,56 \pm 0,31 a$ & $0,68 \pm 0,13 a$ \\
\hline 14 & $\alpha$-Bulneseno & 1506 & $0,99 \pm 0,07 a$ & $1,16 \pm 0,09 a$ & $1,13 \pm 0,05 a$ \\
\hline 15 & $\gamma$-Cadineno & 1515 & $0,17 \pm 0,16 a$ & $0,29 \pm 0,12 a$ & $0,25 \pm 0,14 a$ \\
\hline 16 & $\delta$-Cadineno & 1523 & $3,130,93 a$ & $3,36 \pm 0,65 a$ & $3,32 \pm 0,71 a$ \\
\hline 17 & Germacreno B & 1558 & $0,10 \pm 0,09 b$ & $0,42 \pm 0,03 a$ & $0,45 \pm 0,04 a$ \\
\hline 18 & Ledol & 1570 & $10,99 \pm 3,42 a$ & $9,56 \pm 2,40 a$ & $8,16 \pm 2,46 a$ \\
\hline 19 & Es patulenol & 1578 & $2,55 \pm 0,25 b$ & $3,60 \pm 0,18 a$ & $1,98 \pm 0,03 b$ \\
\hline 20 & Globulol & 1583 & $3,12 \pm 0,23 a$ & $3,73 \pm 0,29 a$ & $2,76 \pm 0,09 a$ \\
\hline 21 & Viridiflorol & 1592 & $1,70 \pm 0,16 a$ & $1,87 \pm 0,10 a$ & $1,55 \pm 0,05 a$ \\
\hline 22 & Guaiol & 1604 & $2,85 \pm 0,57 a$ & $2,79 \pm 0,45 a$ & $2,30 \pm 0,44 a$ \\
\hline 23 & epi- $\alpha$-Cadin ol & 1640 & $0,50 \pm 0,49 a$ & $0,78 \pm 0,06 a$ & $0,83 \pm 0,41 a$ \\
\hline 24 & $\alpha$-Cadinol & 1655 & $1,15 \pm 0,12 a$ & $1,20 \pm 0,03 a$ & $1,08 \pm 0,03 a$ \\
\hline 25 & Eudes ma-4(15), 7-dieno-1 $\beta$-ol & 1691 & $0,41 \pm 0,40 a$ & $0,58 \pm 0,29 a$ & $0,51 \pm 0,26 a$ \\
\hline
\end{tabular}

á́ndice de retenção. 'Médias seguidas pela mesma letra não diferem entre si pelo teste de Tukey ao nível de $5 \%$ de probabilidade. \pm : Erro padrão da média.

(Tabela 3). Desses, apenas o $\alpha$-guaieno apresentou redução no teor, quando armazenado. Os constituintes $\beta$-selineno e germacreno $B$ apresentaram acréscimo quando armazenado durante quatro ou oito meses, enquanto que o espatulenol apresentou elevação do teor relativo apenas quando armazenado por quatro meses. Em gengibre, durante o armazenamento dos rizomas, ocorreram alterações nos teores relativos de alguns constituintes químicos do óleo essencial. O neral e geranial aumentaram cerca de $60 \%$, enquanto que o conteúdo de geraniol e acetato de geranila decresceram durante este período (Sakamura, 1987).

Considerando o processamento pós-colheita e o armazenamento, avaliados no presente trabalho, pode-se concluir que o armazenamento reduziu significativamente o teor de óleo essencial em partes aéreas de carqueja armazenadas na forma pulverizada. Entretanto, quando foi utilizado o armazenamento na forma fragmentada, não se verificou redução no teor de óleo essencial. Por sua vez, como não se verificou qualquer redução dos teores relativos dos constituintes químicos do óleo essencial e, ainda, observou-se uma tendência de elevação do teor de óleo essencial em partes aéreas armazenadas na forma de fragmentos e pulverizadas no momento da extração do óleo, esta metodologia sugere ser a mais indicada para o armazenamento de carqueja. Verificou-se, ainda, que o armazenamento do óleo essencial por até oito meses em congelador não alterou a sua composição química. 


\section{REFERÊNCIA}

ADAMS, R.P. Identification of essential oil components by Gas Chromatography/Mass Spectroscopy. Allured: Illinois, 2001. 456p.

AGRA, M.F.; FRANÇA, P.F.; BARBOSA-FILHO, J.M. Synopsis of the plants known as medicinal and poisonous in Northeast of Brazil. Revista Brasileira de Farmacognosia, v.17, n.1, p.114-40, 2007.

AVANCINI, C.A.M.; WIEST, J.M.; MUNDSTOCK, E. Atividade bacteriostática do decocto de Baccharis trimera (Less.)

DC.; Compositae, carqueja, como desinfetante ou antiséptico. Arquivo Brasileiro de Medicina Veterinária e Zootecnia, v.52, n.3, p.230-4, 2000.

CRAVEIRO, A.A.; FERNANDES, A.G.; ANDRADE, C.H.S. Óleos essenciais de plantas do nordeste. Fortaleza: Editora UFC, 1981. 210p.

DOOL, V.D.; KRATZ, P.D.J.A. Generalization of the retention index system including linear temperature programmed Gas-Liquid Partition Chromatography. Journal of Chromatogrography, v.11, p.463-71, 1963. FERRANTE, L.M.S. et al. GC/FID-based authentication of Baccharis trimera: a quality control study of products commercialized in Curitiba and metropolitan region (Brazil). Revista Brasileira de Farmacognosia, v.17, n.3, 35660, 2007.

GENE, R.M. et al. Anti-inflamatory and analgesic activity of Baccharis trimera: identification of active constituents. Planta Medica, v.62, p.232-5, 1996.

JAKUPOVIC, J. et al. Sequi- and diterpenes fron Baccharis species. Phytochemistry, v.29, n.7, p.2217-22, 1990. JANUÁRIO, A.H. et al. Neo-clerodane diterpenoid, a new metalloprotease snake venom inhibitor from Baccharis trimera (Asteraceae): anti-proteolytic and anti-hemorrhagic properties. Chemico-Biological Interactions, v.150, n.3, p.243-51, 2004.

LOAYZA, I. et al. Essential oils of Baccharis salicifolia, $B$. latifolia and B. dracunculifolia. Phytochemistry, v.38, n.2, p.381-9, 1995.

MAIA, N.B.; BOVI, O.A.; DUARTE, F.R. Obtenção e análise do óleo essencial do gengibre: efeito de secagem e processamento. Bragantia, v.50, n.1, p.83-92, 1991. NESOM, G.L. Infrageneric taxonomy of North and Central American Baccharis (ASTERACEAE: ASTEREAE). Phytologia, v.68, n.6, p.40-6, 1990.

PEDRAZZI, A.H.P. et al. Hematological evaluation of carqueja (Baccharis trimera) infusion. Fitoterapia, v.68, n.1, p.26-9, 1997.

RIBEIRO JÚNIOR, J.I. Análises estatísticas no SAEG. Viçosa: Editora UFV, 2001. 301p.

SAKAMURA, F. Changes in volatile constituents of Zingiber officinale rhizomes during storage and cultivation. Phytochemistry, v.26, n.8, p.2207-12, 1987.

SILVA, F.G. et al. Seasonal variability in the essential oils of wild and cultivated Baccharis trimera. Journal of the Brazilian Chemical Society, v.18, n.5, p.990-7, 2007.

SUTTISRI, R. et al. Neo-clerodane diterpenoids and other constituents from Baccharis genistelloides. Phytochemistry, v.35, n.2, p.443-6, 1994. 